\title{
Editorial 63
}

\author{
Eric Scerri ${ }^{1}$
}

Published online: 10 September 2019

(c) Springer Nature B.V. 2019

The issue opens with a masterly review article by a distinguished Russian author Naum Imyanitov who I had the pleasure of meeting when we both spoke at the recent 4th International Conference on the Periodic Table that was held, appropriately enough, in Saint Petersburg. Imyanitov has published extensively on the subject periodic table over a period of many years (Imyanitov 2016). In the current article he provides a detailed examination of the division of elements into two subsets in two orthogonal senses. First of all there is the question of the early and later elements within any block of the periodic table. This is the phenomenon of internal periodicity which reflects the fact that the elements scandium to manganese, in the d-block for example, show an approximate repetition when one considers the properties of the elements iron to zinc.

Secondly, there is a way of subdividing the periodic table to reflect the similarities between elements that show even as opposed to odd values of the sum of the $n+\ell$ quantum numbers. This property has been recognized since the pioneering work of Biron in 1915 and is otherwise known as secondary periodicity. For example, in the p-block the properties of the elements boron to neon resemble those of the period from gallium to krypton more closely than they do the properties of elements from aluminum to argon and so on.

In addition to providing a wealth of detailed examples to illustrate these internal periodicities if one may call them so, the author also provides numerous references to the work of Russian authors who have examined these and other aspects of the periodic table, as whose work is largely unknown in the West. One can only hope that somebody might be inspired to translate some of these articles for the growing community of scholars who are interested in studying the periodic table, but who are not able to read the original Russian sources.

The second article is written by Amihud Gilead who has contributed previously to this journal (Gilead 2016). His interest lies in the question of "individual pure possibilities" a phrase which he prefers to the more common one of "possible worlds". In the current article Gilead extends his previous views on the prediction of chemical elements to the more general theme of crystallography, and, in particular the discovery of quasicrystals whose possibility was anticipated by several authors.

Few authors have attempted to carry out a comprehensive historical and philosophical analysis of thermodynamics and its connections with the origins of physical chemistry. The simple reason for this state of affairs is that it involves some very difficult material. Raffaele

Eric Scerri

scerri@chem.ucla.edu

1 Department of Chemistry and Biochemistry, UCLA, Los Angeles, CA 90095, USA 
Pisano, the lead author of the third article in the present issue, is an expert in this area and has already distinguished himself by writing about the work of Sadi Carnot, where much of this field can be said to begin (Pisano 2010). The article here is wide ranging and comprehensive and makes ample reference to the huge literature on the subject, including the contributions by Carnot, Clausius, Gibbs as well as Guldberg and Waage. The analysis focuses on some key concepts such as entropy, reversible processes, heat, temperature and thermal equilibrium, as well as engaging in the educational aspects of these concepts.

Peter Nelson has been a frequent contributor to the journal, whose interests span a wide range of topics from chemical education to electronic structure, the periodic table and thermodynamics (Johnson and Nelson 2018). In the current issue Nelson grapples with the question of explaining the notion of temperature in terms statistical mechanics. His approach involves showing that the reciprocal of temperature $(1 / \mathrm{T})$ corresponds to the relative change in the number of microstates of a system as a function of the change in internal energy.

The final full-length article is by a newcomer to Foundations of Chemistry, namely Carlos Santana, who is no relation to the famous Latin-Rock musician, but a philosopher based at the University of Utah. I first encountered this author when he delivered a spectacularly good lecture at the Philosophy of Science Association meeting in Seattle. His attention to scientific details, in contrast to much of what passes as philosophy of science these days, compelled me to approach him after the lecture and suggest that he might contribute an article to us. Here Santana argues that mineralogists have no use for natural kinds in that the classification of minerals does not reflect clear-cut natural subdivisions, but rather human intentionality. Such a conclusion may well come as a disappointment to philosophers of science who like to invoke natural kinds in far more 'messy' domains such as biological species or psychological disorders.

The issue closes with a book review, by the Florida based philosopher Elijah St. Germain, of Giovanni Villani's book on chemistry as an example of "systematic complexity".

\section{References}

Gilead, A.: Eka-elements as chemical pure possibilities. Found. Chem. 18, 183-194 (2016)

Imyanitov, N.: Spiral as the fundamental graphic representation of the Periodic Law. Blocks of elements as the autonomic parts of the Periodic System. Found. Chem. 18, 153-173 (2016)

Johnson, D.A., Nelson, P.G.: Valencies and lanthanides. Found. Chem. 20, 15-27 (2018)

Pisano, R.: On principles in Sadi Carnot's thermodynamics (1824). Epistemological reflections. Almagest 2(1), 128-179 (2010)

Publisher's Note Springer Nature remains neutral with regard to jurisdictional claims in published maps and institutional affiliations. 